\title{
Numerical bifurcation analysis for a prey-predator type interactions with a time lag and habitat complexity
}

\author{
Aytül GÖKÇE* \\ Ordu University, Faculty of Science and Arts, Department of Mathematics, Ordu, Turkey \\ (ORCID: 0000-0003-1421-3966)
}

\begin{abstract}
In this paper, a two-component generic prey-predator system incorporated with habitat complexity in predator functional response, and with constant time delay in predator gestation is considered. Although the role of time delay on the system dynamics is widely studied in the literature, only a few researchers have addressed the effect of habitat complexity in the prey-predator type interactions. In the first part of the paper the equilibria and stability analysis of the mathematical model is mentioned. In the second part, particular attention is paid on the numerical bifurcation analysis of the prey and predator densities based on two system parameters:(i) the strength of homogeneous habitat complexity and (ii) predator attack rate with and without time delay. It is found that dynamics with time delay in predator gestation are found to be much richer compared to that without time delay. The system stability may change from stable to unstable through a Hopf bifurcation and the solution branches emanating from these Hopf points are usually stable and supercritical. However, delay driven system may lead unstable orbits arising from Hopf bifurcations. It is also found that increasing the strength of habitat complexity may lead the stability change from unstable to stable.
\end{abstract}

Keywords: Habitat complexity, delay differential equations, numerical bifurcation analysis.

\section{Gecikme ve yaşam alanı karmaşıklığı eklenmiş av-avcı tipindeki etkileşimler için nümerik çatallanma analizi}

\begin{abstract}
Öz
Bu makalede avcı türü reaksiyonuna yaşam alanı karmaşıklığı ve olgunlaşma evresine sabit bir gecikme eklenerek elde edilen genel bir iki bileşenli av-avcı sistemi dikkate alınmıştır. Zaman gecikmesinin sistem dinamiklerine etkisi geniş bir şekilde literatürde çalışılmış olmasına ragmen, sadece birkaç araştırmacı av-avcı tipinde etkileşimlerde yaşam alanı karmaşıklığının etkilerini ele almıştır. Makalenin ilk bölümünde denge noktaları ve matematiksel modelin kararlılık analizinden bahsedilmiş̧ir. İkinci kısımda av ve avcı türlerinin yoğunluklarının gecikmeli ve gecikmesiz durumlarda yapılan nümerik çatallanma analizine iki parametreye bağlı olarak dikkat çekilmiştir:(i) homojen yaşam alanı karmaşıklı̆ııın etkinlik parametresi ve (ii) avcı saldırı oranı parametresi. Gecikmesiz sistemde dinamiklerin kararlılığının Hopf çatallanması ile kararlı durumdan kararsız duruma değiştiği ve bu Hopf noktalarından yayılan dalların genelde kararlı ve süper kritik olduğu gözlemlenmiştir. Buna rağmen, gecikme kaynaklı sistem ise Hopf çatallanmadan çıkan kararsız yörüngelere sebep olabilir. Aynı zamanda yaşam alanı karmaşıklığının etkinliğini artırmanın sistem dinamiklerinin kararsız durumdan kararlı duruma geçmesine sebep olduğu bulunmuştur.
\end{abstract}

Anahtar kelimeler: Yaşam alanı karmaşıklığı, gecikmeli diferansiyel denklemler, nümerik çatallanma analizi.

\section{Introduction}

The term habitat usually refers to an environment where particular species of organisms survive. As a place, a habitat has principle components such as water, food, shelter and space, with which species can reproduce and survive [1-3]. The influence of habitat complexity is usually studied in ecological models and has taken a great role in the prey-predator dynamics. Predation is one of the key factors for

${ }^{*}$ Corresponding author: aytulgokce@odu.edu.tr

Received:13.12.2020, Accepted:18.02.2021 
structuring a community and predator functional response, that can be introduced as the amount of prey catch by predator per unit time, is influenced by complexity of the habitat [1]. Habitat complexity has a great impact on the distribution of prey-predator interactions, thus it is also one of the useful mechanisms for the structure of a population [1-3]. Incorporating habitat complexity in the population, the particular objective is to reduce the encounter rates between prey and predator, i.e. decrease the predation rates in the system. Therefore, structural complexity of the habitat may have a substantial effect on the predator functional response [4,5]. Lower foraging behaviour or increase in the strength of habitat complexity may effectively stabilise the dynamics for predator-prey interactions by reducing the encounter rates between these species [1]. In fact, understanding population behaviour with a decreasing probability of prey capture due to lower foraging efficiency of predator is a significant direction for prey-predator interactions and has been mostly overlooked by the scientific community.

Time delay occurs in almost all biological situations and usually considered in the growth rates of prey and predator species. In fact, an organism does not instantly digest its food and some conversion processes, e.g. reproduction rate and gestation, from one state (prey biomass) to another state (predator biomass) occur in such systems [6]. Thus it is already documented that more realistic and complex dynamical behaviour may be obtained in the presence of constant time delay between interacting species [6-10]. Since time delay is already recognised to have an essential impact on the stability results of population dynamics, differential equations with time delay have attracted a great attention over several decades to develop many realistic mathematical models in ecology and biology [6, 11-13]. Some of the papers published recently has resulted in extremely rich repertoire of dynamical patterns, considering local and non-local time delays in the maturation and gestation period of prey and predator species [6, $14,15]$. In order to understand the realistic mechanism of prey-predator interactions, taking dynamical analysis with additional contribution of time delay into consideration is therefore required.

In this paper, a two-component non-linear model of prey-predator interactions with habitat complexity and time delay is analysed in terms of model dynamics and numerical bifurcation. The model is based on the paper [1], where the role of time delay is analysed through Hopf bifurcation analysis without delving into bifurcation analysis. For this purpose, the system behaviour can be investigated more succinctly and the role of habitat complexity and predator attack rate should be comprehensively studied in the absence and presence of predator gestation delay. Thus, the large spectrum of limit cycle dynamics and periodic oscillations can be obtained by considering these additional mechanisms for prey-predator interactions.

This paper is organised as follows. In the next section, the mathematical model considered in this paper is described. Section 3 is devoted to analyse numerical bifurcations of the densities of prey and predator species with respect to two main parameters of the model: the strength of habitat complexity and predator attack rate. These analyses are performed for varying degree of time delay in the gestation period and rich dynamical activity with Hopf bifurcations (HB), transcritical bifurcations (TCB) and period doubling bifurcations (PD) are observed. Lastly, in Section 4, the results of this paper are summarised and potential future directions are presented.

\section{Mathematical Model Formulation}

The general prey-predator type model analysed with habitat complexity and constant time delay in this paper is based on the system presented in [1]:

$$
\begin{gathered}
\frac{\mathrm{d} z(t)}{\mathrm{d} t}=r z(t)\left(1-\frac{z(t)}{\kappa}\right)-\frac{\alpha(1-c) z(t) v(t)}{1+\alpha(1-c) h z(t)} \\
\frac{\mathrm{d} v(t)}{\mathrm{d} t}=\frac{\theta \alpha(1-c) z(t-\eta) v(t-\eta)}{1+\alpha(1-c) h z(t-\eta)} \\
z(\varphi)=\psi_{1}(\varphi), \quad v(\varphi)=\psi_{2}(\varphi), \quad \varphi \in(-\eta, 0],
\end{gathered}
$$

where parameter $r$ represents the prey population growth rate and $\kappa$ stands for the environmental carrying capacity. The $\theta$ gives the conversion efficiency rate for which the number of new-born 
predators is measured for each captured prey [3]. The delay rate $\eta$ is the constant time that is needed for predator maturation. Holling type II functional response is used for the given prey-predator model, where $\alpha$ represents the predator attack rate and $h$ stands for the handling time needed for prey [3]. In order to incorporate the habitat complexity, that decrease foraging or search activity of predator, the predator attack rate $(\alpha)$ is replaced with $\alpha(1-c)$. Therefore, larger $c$ leads to a decrease in the predator attack rate. Here $c \in(0,1)$ is a non-dimensional parameter to measure the strength of habitat complexity, see $[1,3,16]$ for further details.

\subsection{Equilibria:}

The model given by equations (1) -(2) has three possible steady states:

- the trivial state exist for all parameters, i.e. $S_{00}=(0,0)$,

- the predator free steady state, i.e. $\boldsymbol{S}_{+0}=(\kappa, 0)$,

- the coexisting state, i.e. $\boldsymbol{S}_{++}=\left(z_{+}, v_{+}\right)$,

where

and

$$
z_{+}=\frac{d}{\alpha(\theta-h d)(1-c)}
$$

$$
v_{+}=\frac{1}{\kappa}\left(\frac{r\left(\kappa-z_{+}\right)}{(1-c) \alpha}+r h\left(\kappa-z_{+}\right) z_{+}\right)
$$

For their biological meaning, $z_{+}$and $v_{+}$values should be positive, thus must satisfy the constrains $h d+d / \alpha \kappa<\theta<1$ and $c<1-d / \alpha \kappa(\theta-h d)$. In the rest of the paper, the numerical bifurcation results of the two-component prey-predator type model with habitat complexity presented in equations (1) -(2) are shown. Since the main interest is to understand the role of habitat complexity on the dynamics, particular objective will be to explore the bifurcation diagrams of prey and predator components based on two parameters, i.e. $c$ and $\alpha$. Here $c$ represents the strength of habitat complexity and $\alpha$ represents the predator's attack rate. One of the most obvious signs of delay driven differential equations is the existence of Hopf bifurcation, where a pair eigenvalues with purely imaginary part exists and all other remaining eigenvalues are found with a negative real part [6]. Crossing the Hopf point, instability is observed through a limit cycle. One should note that the model has two eigenvalues in the absence of delay, whereas delay driven model may lead to infinitely many eigenvalues. A particular focus will be on the stability of the system around the positive coexisting state, that is $S_{++}=\left(z_{+}, v_{+}\right)$,. Parameters used here are based on the paper [1], and fixed to $r=3.3, \kappa=898, \alpha=0.045, c=0.8$, $h=0.0437, d=1.06, \theta=0.215$.

In Figure 1, time simulations of prey and predator densities are shown for different delay parameters $\eta$. When there is no delay in the system $(\eta=0)$, stable dynamics with damping oscillations are observed and densities of prey and predator species are found to be stable, as in Figure 1(a). For a chosen parameter space, the critical threshold for delay is found to be $\eta \simeq 0.461$, where the system becomes unstable through a Hopf bifurcation. The model presents unstable dynamics when time delay is above this threshold, e.g. $\eta=0.6$ as given in Figure 1(b). Higher amplitude periodic oscillations with a larger limit cycle can be seen with $\eta=3.5$ in Figure 1(c). Interestingly, chaotic behaviour can be observed further away from Hopf bifurcation with a further increase in delay, as in Figure 1(d), where random oscillations can be obtained at the initial stages of the time dependent prey $(z)$ and predator $(v)$ densities. 

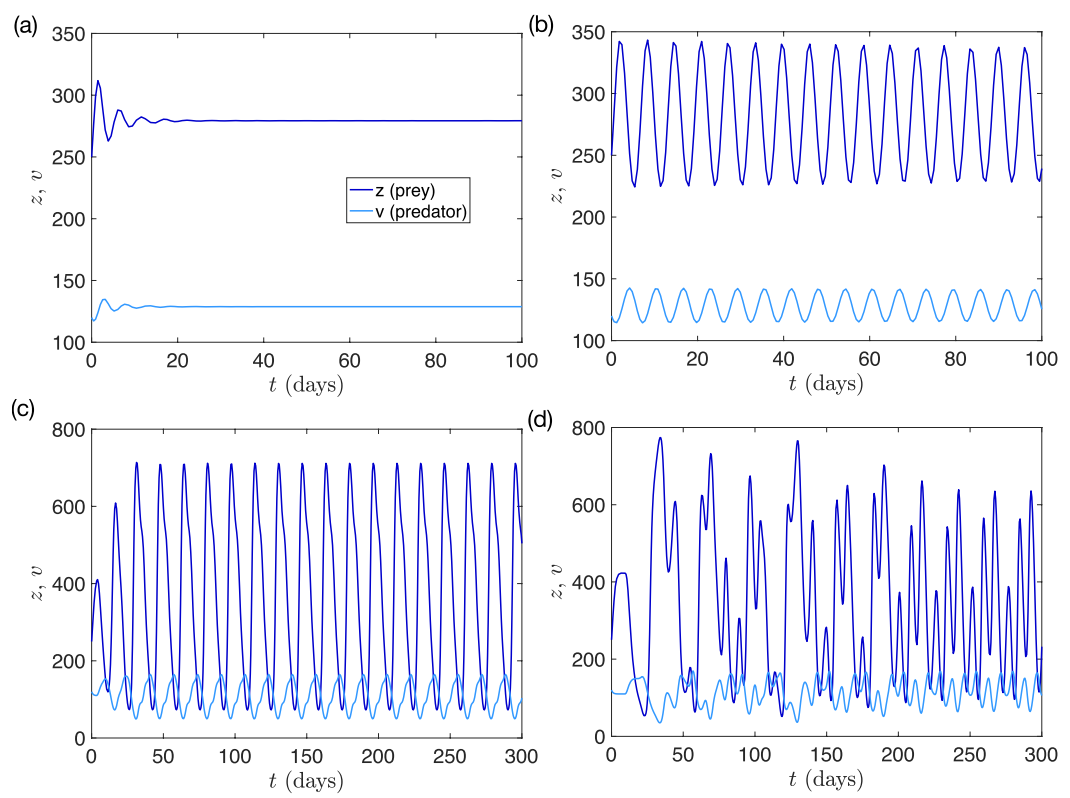

Figure 1. Time evolutions of two-component prey-predator model given by (1) -(2) based on different values of time delay $\eta=0$ (a), $\eta=0.6$ (b), $\eta=3.5$ (c) and $\eta=9.5$ (d) with initial conditions $\left(z_{0}, v_{0}\right)=(250,120)$.

The system dynamics can be alternatively shown using corresponding phase trajectories in time, see Figure 2. Here the red star stands for the initial condition and green star represents the end point of the trajectories. When the system is stable, see Figure 2(a), trajectories approaches to a positive steady state, and that is unstable as trajectory gets away from this steady state, see Figure 2(b,c,d).

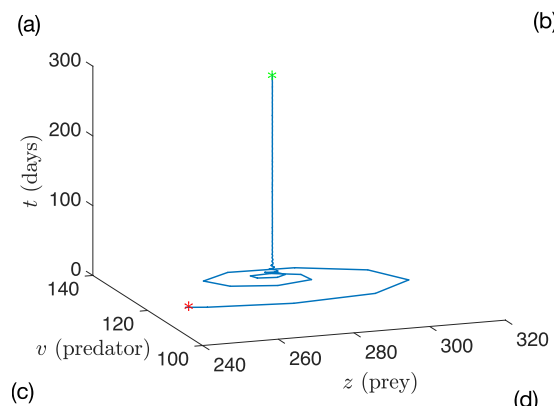

(b)
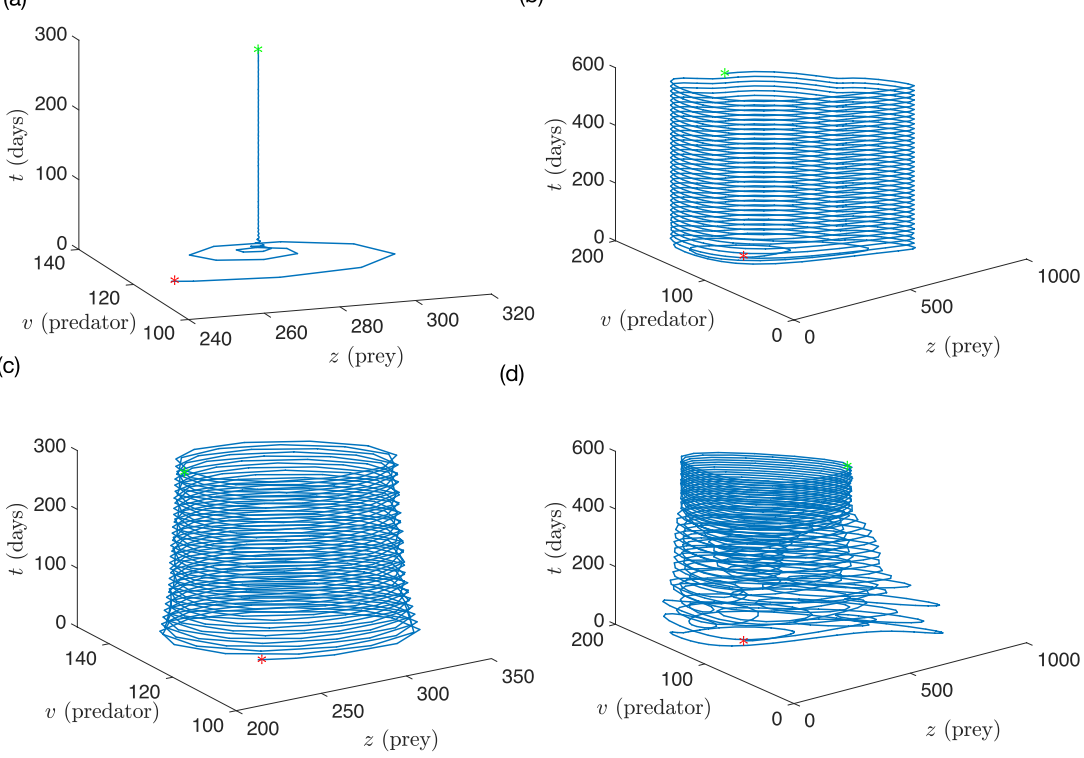

Figure 2. The phase portraits corresponding to time simulations presented in Figure 1 for $\eta=0$ (a), $\eta=0.6$ (b), $\eta=3.5$ (c) and $\eta=9.5$ (d).

In Figure 3, the densities of prey and predator species are plotted with respect to time for sufficiently long time. As seen, dynamics with chaotic behaviour that is observed for $t<$ 400 eventually switches to periodic oscillations when $t>400$. This confirms the results given in Figure 1(d), where random oscillations are initially obtained before the system settles down to a regular behaviour. Therefore, much higher time delay in the system may induce irregular population dynamics. 




Figure 3. Time evolution of two component model presented in Figure $1(\mathrm{~d})$ is simulated for $t \in[0,600]$ for $\eta=$ 9.5.

Now the local stability of the system around the positive coexisting state will be discussed and the instability induced by constant time delay will be analysed. Here the periodic dynamical oscillations occur through Hopf bifurcation, for which a critical time delay crosses a critical threshold and only a pair of imaginary eigenvalues appear. In this context, the local stability of the model can be investigated by constructing the Jacobian matrix at the equilibria. For this purpose, linearization method is used for the main model. Following the linearization of the system, characteristic matrix for the non-delayed part of the model is given by

$$
M=\left(\begin{array}{cc}
r\left(1-\frac{2}{\kappa} z_{+}\right)-\frac{\alpha(1-c) v_{+}}{\left(1+\alpha(1-c) h z_{+}\right)^{2}} & \frac{\alpha(1-c) z_{+}}{1+\alpha(1-c) h z_{+}} \\
0 & -d
\end{array}\right)
$$

and that for the delayed part of the model is

$$
M^{\eta}=\left(\begin{array}{cc}
0 & 0 \\
\frac{\theta \alpha(1-c) v_{+}}{\left(1+\alpha(1-c) h z_{+}\right)^{2}} & \frac{\theta \alpha(1-c) z_{+}}{\left(1+\alpha(1-c) h z_{+}\right)}
\end{array}\right)
$$

Therefore the model presented in equations (1) -(2) can be rewritten in a closed form of

$$
\frac{\mathrm{d}}{\mathrm{d} t} \Xi(t)=M \Xi(t)+M^{\eta} \Xi(t-\eta)
$$

where $\boldsymbol{\Xi}=(z, v)$.

The corresponding characteristic equation is then given as

$$
\left|M+M^{\eta} \mathrm{e}^{-\zeta \eta}-\zeta I_{2}\right|=0
$$

where $|\cdot|$ represents the determinant and $\zeta$ stands for the eigenvalue around the positive coexisting state.

In the absence of time delay, characteristic matrix for the trivial steady state becomes

$$
M_{00}=\left(\begin{array}{cc}
r & 0 \\
0 & -d
\end{array}\right)
$$

and corresponding eigenvalues are easily found as $\zeta_{1}=-r$ and $\zeta_{2}=d$. Thus trivial state $\mathbf{S}_{00}=(0,0)$ is always a saddle point. 
Characteristic matrix for predator-free state $S_{+0}=(\kappa, 0)$ can be similarly given as

$$
M_{+0}=\left(\begin{array}{cc}
r\left(1-\frac{2 z_{+}}{\kappa}\right) & -\frac{\alpha(1-c) z_{+}}{1+\alpha(1-c) h z_{+}} \\
0 & -d+\frac{\theta \alpha(1-c) z_{+}}{\left(1+\alpha(1-c) h z_{+}\right)}
\end{array}\right) \text {, }
$$

with corresponding eigenvalues

and

$$
\zeta_{1}=r\left(1-\frac{2 z_{+}}{\kappa}\right)
$$

$$
\zeta_{2}=-d+\frac{\theta \alpha(1-c) z_{+}}{\left(1+\alpha(1-c) h z_{+}\right)}
$$

The stability of the predator-free system depends on the choice of parameters. Considering the eigenvalues at a form:

$$
\zeta(\eta)=\xi(\eta)+i \omega(\eta)
$$

where $\xi$ and $\omega$ are real numbers and $\eta$ is the delay rate. When $\eta=0$ (no delay), the coexisting state $\boldsymbol{S}_{++}=\left(z_{+}, v_{+}\right)$is stable if $\xi(0)<0$ and unstable if $\xi(0)>0$. When $\eta>0$ but chosen sufficiently small, $\boldsymbol{S}_{++}=\left(z_{+}, v_{+}\right)$becomes still stable. Here the stability change occur at a critical value of $\eta$ for which

$$
\xi(\eta)=0 \quad \text { and } \quad \omega(\eta) \neq 0
$$

thus $\zeta(\eta)$ in equation (9) becomes purely imaginary. When $i \omega(\eta)$ is a root of the equation (6), critical threshold for delay $\eta_{c}$ can be found by replacing $\zeta=i \omega$ in the characteristic equation and solving it for $\eta$. For this purpose, the result of the characteristic equation given in equation (6) is found as

$$
\zeta^{2}-\operatorname{Trace}(M) \zeta+\operatorname{Det}(\mathrm{M})+K_{1} \mathrm{e}^{-\zeta \eta}-K_{2} \zeta \mathrm{e}^{-\zeta \eta}=0,
$$

where $M$ is given in equation (3). Here $K_{1}$ and $K_{2}$ are described as

$$
\begin{gathered}
K_{1}=M_{11} M^{\eta}{ }_{22}-M^{\eta}{ }_{21} M_{12}, \\
K_{2}=M^{\eta}{ }_{22} .
\end{gathered}
$$

Substituting $\zeta=i \omega$ in equation (10) the following pair of equations are obtained:

from which one obtains

$$
\begin{aligned}
& K_{1} \cos \omega \eta-K_{2} \omega \sin \omega \eta=\omega^{2}-\operatorname{Det}(M), \\
& K_{2} \omega \cos \omega \eta+K_{1} \sin \omega \eta=-\omega \operatorname{Trace}(\mathrm{M}),
\end{aligned}
$$

$$
\left(K_{1}^{2}+\left(K_{2} \omega\right)^{2}\right) \cos \omega \eta=K_{1}\left(\omega^{2}-\operatorname{Det}(M)\right)-K_{2} \omega^{2} \operatorname{Trace}(\mathrm{M}) .
$$

The solution of these equations leads to a fourth order polynomial of $\omega$, that can be reduced to a second order by replacing $\mathrm{V}=\omega^{2}$. As a result a critical threshold for the Hopf bifurcation can be found as 


$$
\eta=\frac{1}{\omega} \operatorname{acos} \frac{K_{1}\left(\omega^{2}-\operatorname{Det}(M)\right)-K_{2} \omega^{2} \operatorname{Trace}(\mathrm{M})}{K_{1}{ }^{2}+\left(K_{2} \omega\right)^{2}} .
$$

As mentioned above, periodic oscillations occur when discrete time delay crosses this critical value. In the next section, we the analytical formulations above will be validated using numerical simulations for single parameter continuation.

\section{Numerical Bifurcation Analysis}

To validate the theoretical study given in the previous section, some numerical bifurcation analysis of the prey-predator system (1)-(2) is performed in this section. With the exception of the strength of habitat complexity $(c)$ and the predator's attack rate $(\alpha)$, all parameters are fixed to their biologically meaningful values given in the previous section. Since habitat complexity plays an essential role of prey-predator interactions in ecology, this paper mainly concentrates on the model analysis based on the degree of habitat complexity. Figure 4 represents bifurcation diagrams of prey dynamics with respect to habitat complexity strength (c) with $\eta=0$ and $\eta=0.6$. The number of unstable eigenvalues $\left(\lambda_{s}\right)$ is associated with solid, dashed and dotted lines. Two positive critical values, which can be stable or unstable depending on the parameter $(c)$ for prey, are shown in the absence $(\eta=0)$ and presence $(\eta=0.6)$ time delay. In Figure 4(a), Hopf bifurcation (HB) is surrounded with a stable limit cycle around the coexisting state at a critical value of $c=0.1227$. On the other hand, the predator-free steady state is unstable when $c<0.8445$. Two steady states move to each other and transcritical bifurcation (TCB) occurs at $c=0.8445$. Further away from this point, predator free state is stable with $\lambda_{s}=0$ and coexisting state is unstable with $\lambda_{s}=1$. The delayed prey-predator system with habitat complexity, see Figure 4(b), still has a transcritical bifurcation, implying that transcritical bifurcation is independent of time delay. An additional Hopf bifurcation is detected at $c=1.229$ in the presence of delay. One may also analyse the branches emanating from Hopf bifurcations. In the non-delayed case, see Figure 4(a), the branches emanating from Hopf bifurcations around coexisting state is stable, whereas a branch of Hopf bifurcation with respectively stable and unstable dynamics can be observed around predator-free state for delayed case at $c=0.5568$ and $c=1.229$ in Figure 4(b). In these orbits, stable and unstable dynamics collide in a period doubling bifurcation (PD).


Figure 4. Numerical bifurcation plot of prey $z$ with respect to parameter $c$ without (a) and with (b) time delay for $\eta=0.6$. The unstable eigenvalues are given by solid $\left(\lambda_{s}=0\right)$, dashed $\left(\lambda_{s}=1\right)$ and dotted $\left(\lambda_{s}=2\right)$ lines. Inset in (b) represent the orbit emanating from Hopf bifurcations.

In Figure 5, an analysis of the predator in the system (1)-(2) with and without the impact of time delay is determined using the stability of the equilibria under the variation of parameter $c$. The system shows various dynamics including Hopf bifurcation, transcritical bifurcation and periodic doubling bifurcation. For the non-delayed case, the stability of the predator species is visualised in Figure 5(a), where one transcritical $(c=0.8445)$ and one supercritical Hopf bifurcation $(c>0.1227)$ surrounded with a stable limit cycle are detected. Note that there is only trivial steady state that is stable when $(c>$ 0.8445) Switching from non-delayed case to delayed case in Figure 5(b), numerical bifurcation analysis of the positive equilibrium is shown under the change of parameter $c$ and one more Hopf bifurcation 
appears, that is a similar behaviour to the prey dynamics, shown in Figure 4(b). One should note that the maximum value for $\lambda_{s}$ is found to be 2 . Furthermore, transcritical bifurcation is observed as the strength of habitat complexity (c) crosses a critical value, where predator population goes to extinction at $\mathrm{c}=0.8445$.

(a)

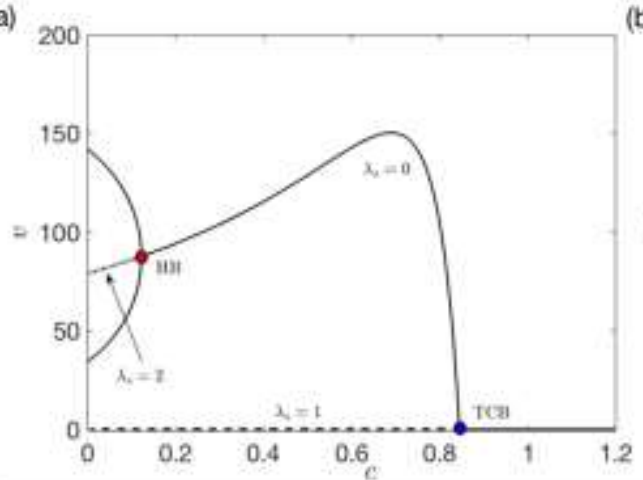

(b)

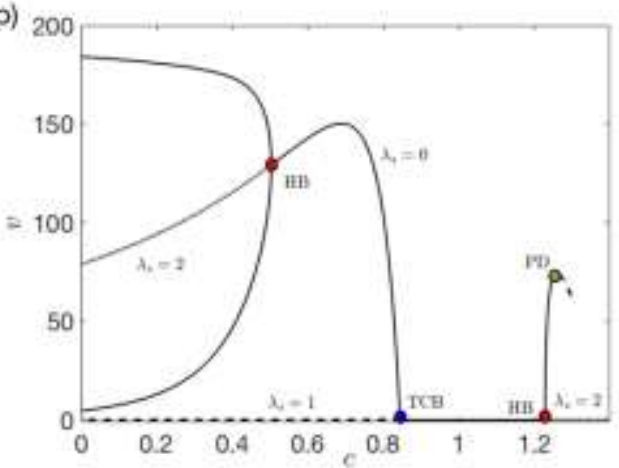

Figure 5. Bifurcation diagram of predator $v$ as a function of the habitat complexity strength $c$ in the absence (a) and presence (b) of time delay with $\eta=1.4$. The unstable eigenvalues are given by solid $\left(\lambda_{s}=0\right)$, dashed $\left(\lambda_{s}=\right.$ 1) and dotted $\left(\lambda_{s}=2\right)$ lines.

A further numerical analysis of the prey and predator densities with respect to predator's attack rate $(\alpha)$ are presented in Figure 6 and Figure 7. As seen, no interesting dynamics can be observed for $\alpha<0.014$ for both delayed and non-delayed cases. Predator-free state is always unstable for varying values of $\alpha(\alpha>0.014)$ with $\lambda_{\mathrm{s}}=1$, whereas the coexisting state is stable for $\alpha<0.07896$ and instability occurs through a Hopf bifurcation away from $\alpha=0.07896$. Incorporating time delay as in Figure 6(b), an additional Hopf bifurcation is detected on a predator-free state, where the number of unstable eigenvalues change from 1 to 3 . In addition, different from other cases, the solution branches emanating from this Hopf bifurcation at $\alpha=0.159$ are unstable.


Figure 6. Numerical bifurcation of prey $z$ as a function of predator's attack rate $\alpha$ without (a) and with time delay $(\eta=1.4)(\mathrm{b})$. Solid line $\left(\lambda_{s}=0\right)$, dashed line $\left(\lambda_{s}=1\right)$, dotted line $\left(\lambda_{s}=2\right)$ and the line with a square marker $\left(\lambda_{s}=3\right)$ correspond to the number of eigenvalues with positive real part (unstable) determined on the branches. In both (a) and (b), branches of periodic orbits of the Hopf points are shown. The inset in (a) represents the zoomed plot for branch emanating from Hopf bifurcation.

In Figure 7, the behaviour of the predator $\mathrm{v}$ under different attack rate $\alpha$ is shown. Compared to the predator dynamics with respect to the habitat complexity strength $(c)$ presented in Figure 5, simpler dynamics can be observed considering a variation of $\alpha$. One obvious result of Figure 6 and Figure 7 would be that the solution branches emanating from delay driven Hopf bifurcations show unstable dynamics, whereas delay induced Hopf bifurcations in Figure 4 and Figure 5 represent the combination of stable and unstable branches with a periodic doubling bifurcation. Namely, following the branches arising from Hopf points, the stability can be lost or gained via a periodic doubling bifurcation. Furthermore, the maximum number of unstable eigenvalues are increased for numerical bifurcation in terms of $\alpha$. It is also worth mentioning that, for all cases, the richer bifurcation dynamics can be observed 
increasing the values of time delay. In summary, the increase in the strength of habitat complexity $(c)$ induce stability in general, whereas the increase in time delay in predator gestation lead instability in the population densities around the equilibria.

(a)

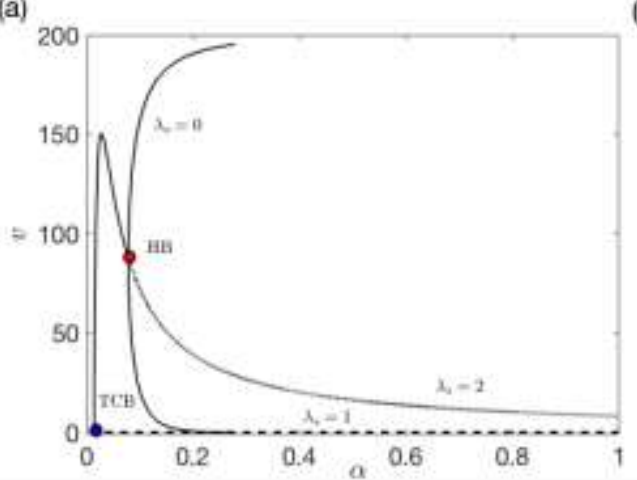

(b)

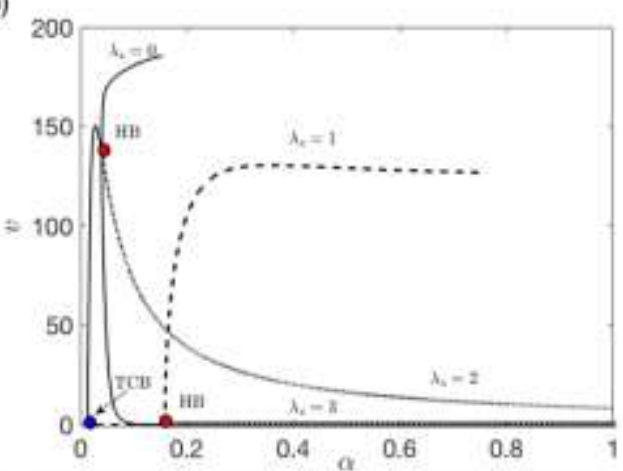

Figure 7. Numerical bifurcation of predator $v$ density with respect to the predator's attack rate $\alpha$ without (a) and with time delay $(\eta=1.4)$ (b). Solid line $\left(\lambda_{s}=0\right)$, dashed line $\left(\lambda_{s}=1\right)$, dotted line $\left(\lambda_{s}=2\right)$ and the line with a square marker $\left(\lambda_{s}=3\right)$ correspond to the number of eigenvalues with positive real part (unstable) determined along the branches.

\section{Conclusion}

This paper demonstrates that incorporating habitat complexity and constant time delay in a generic pre-predator type model can have a substantial impact on the stability and numerical bifurcation of the dynamics. Here, time delay is already recognised somewhat more realistic by the scientific community $[6,13,14]$.Thus, adding delay term in the model provides an opportunity for analysing the properties of delay deriven Hopf bifurcations, where stability usually changes from stable to unstable. In fact, increasing the delay rate, much richer dynamics may be observed and further analysis of the branches arising from Hopf bifurcations may lead very complex behaviour. In particular, it is possible to observe multiple Hopf points in the presence of predator gestation delay, where solution orbits arising from additional Hopf bifurcation, which appears with time delay, can display other type of bifurcations including period doubling bifurcation. Here, time simulations and phase trajectories of the model presented in equations (1) -(2) are simulated using MATLAB 2017 and parameter continuation and numerical bifurcation with and without delay are studied using DDE-BIFTOOL software $[16,17]$. Numerical simulations for delay differential equations require the history function for time, and that is chosen as a constant vector $\left(z_{0}, v_{0}\right)=(250,120)$. The analysis of the prey and predator dynamics is performed in a single parameter for (i) habitat complexity and (ii) predator attack rate. DDE-BIFTOOL is a collection of MATLAB routines that provides the numerical continuation based on specific parameters and allows the computation for local stability of the steady states.

A further investigation of the model presented here would be to use of brownian motion to explore the stochastic effects in the system with habitat complexity and time delay $[2,18]$. Another extension of this work would be to make a qualitative study for the effect of delay not only in time but also in space, implying that a nonlocal delay in the maturation of predator response [20]. These topics are deferred to future work.

\section{Author's Contributions}

The author developed the theoretical formulations and performed the numerical simulations using MATLAB and DDE-BIFTOOL software. The author has also written the original manuscript and made substantial contributions to conception. Finally, the author gave final approval of the current version and any revised version to be submitted to the journal.

\section{Statement of Conflicts of Interest}

No potential conflict of interest was reported by the author. 


\section{Statement of Research and Publication Ethics}

The author declares that this study complies with Research and Publication Ethics.

\section{References}

[1] Bairagi N., Jana D. 2011. On the stability and Hopf bifurcation of a delay-induced predator-prey system with habitat complexity. Applied Mathematical Modeling, 35 (7): 3255-3267.

[2] Dubey B.K., Maiti A.P. 2019. Global stability and Hopf-bifurcation of prey-predator system with two discrete delays including habitat complexity and prey refuge. Communications in Nonlinear Science and Numerical Simulation, 67: 528-554.

[3] Bairagi N., Jana D. 2012. Age-structured predator-prey model with habitat complexity: oscillations and control. Dynamical Systems, 27 (4): 475-499.

[4] Ghorai S., Poria S. 2016. Turing patterns induced by cross-diffusion in a predator-prey system in presence of habitat complexity. Chaos, Solitons \& Fractals, 91: 421-429.

[5] Din Q. 2017. Complexity and chaos control in a discrete-time prey-predator model. Communications in Nonlinear Science and Numerical Simulation, 49: 113-134.

[6] Gökçe A., Yazar S., Sekerci Y. 2020. Delay induced nonlinear dynamics of oxygen-plankton interactions. Chaos, Solitons \& Fractals, 141: 110327.

[7] Chakraborty K., Chakraborty M., Kar T.K. 2011. Bifurcation and control of a bioeconomic model of a prey-predator system with a time delay. Nonlinear Analysis Hybrid Systems, 5 (4): 613-625.

[8] Liao T., Yu H., Zhao M. 2017. Dynamics of a delayed phytoplankton-zooplankton system with Crowley-Martin functional response. Advances in Difference Equations, 2017 (1): 1-30.

[9] Tang Y., Zhou L. 2007. Stability switch and Hopf bifurcation for a diffusive prey-predator system with delay. Journal of Mathematical Analysis and Applications, 334 (2): 1290-1307.

[10] Yu H., Zhao M., Agarwal R.P. 2014. Stability and dynamics analysis of time delayed eutrophication ecological model based upon the Zeya reservoir. Mathematics and Computers in Simulations, 97: 53-67.

[11] Chattopadhyay J., Sarkar R.R., El Abdllaoui A. 2002. A delay differential equation model on harmful algal blooms in the presence of toxic substances. Mathematical Medicine and Biology: A Journal of IMA, 19 (2): 137-161.

[12] Jiang Z., Wang L. 2017. Global Hopf bifurcation for a predator-prey system with three delays. International Journal of Bifurcation and Chaos, 27 (7): 1750108.

[13] Misra A.K., Chandra P., Raghavendra V. 2011. Modeling the depletion of dissolved oxygen in a lake due to algal bloom: Effect of time delay. Advances in Water Resources, 34 (10): 1232-1238.

[14] Rehim M., Imran M. 2012. Dynamical analysis of a delay model of phytoplankton--zooplankton interaction. Appllied Mathematical Modeling, 36 (2): 638-647.

[15] Sharma A., Sharma A.K., Agnihotri K. 2015. Analysis of a toxin producing phytoplanktonzooplankton interaction with Holling IV type scheme and time delay. Nonlinear Dynamics, 81 (1-2): 13-25.

[16] Jana D., Bairagi N. 2014. Habitat complexity, dispersal and metapopulations: Macroscopic study of a predator--prey system. Ecological Complexity, 17: 131-139.

[17] Engelborghs K., Luzyanina T., Roose D. 2002. Numerical bifurcation analysis of delay differential equations using DDE-BIFTOOL. ACM Transactions on Mathematical Software, 28 (1): $1-21$.

[18] Engelborghs K., Luzyanina T., Samaey G. 2000. DDE-BIFTOOL: a Matlab package for bifurcation analysis of delay differential equations. TW Report, 305: 1-36.

[19] Ji C., Jiang D., Li X. 2011. Qualitative analysis of a stochastic ratio-dependent predator-prey system. Journal of Computational and Applied Mathematics, 235 (5): 1326-1341.

[20] Han B.S., Wang Z.C. 2018. Turing patterns of a Lotka-Volterra competitive system with nonlocal delay. International Journal of Bifurcation and Chaos, 28 (7): 1830021. 